recommendations for axial spondyloarthritis. Ann Rheum Dis. 2017 [Epub ahead of print].

Acknowledgements: This study was conducted thanks to an unrestricted grant from MSD.

Disclosure of Interest: None declared

DOI: 10.1136/annrheumdis-2017-eular.4730

\section{AB0695 DOSE TAPERING OF INFIXIMAB IN PATIENTS WITH SPONDYLOARTHRITIS}

M. Correyero, J.C. Nieto, C.M. González, A. López, R. González, C. Saenz, L. García-Montoya, F.J.L. Longo, I. Monteagudo. Rheumatology Department, Hospital General Universitario Gregorio Marañon, Madrid, Spain

Background: Infliximab have proven to be effective in spondyloarthritis. Previous studies suggest that patients in clinical remission may benefit from dose reduction or pharmacological tapering without relapse.

Objectives: To study the evolution of clinical activity and physical function in patients with spondyloarthritis, ankylosing spondylitis (AS) and psoriatic arthritis (PsA) under Infliximab (IFX) tapering strategy.

Methods: This is a prospective single-centre observational study of patients diagnosed with AS and PsA treated with IFX ( $5 \mathrm{mg} / \mathrm{kg} /$ infusion) between January 1, 2012 and December 31, 2015. We included patients who achieved clinical remission or low activity index (expressed with BASDAI and BASFI) and decided to lower the dose of 5 to $4 \mathrm{mg} / \mathrm{kg} /$ infusion, maintaining the periodicity of the treatment in each patient. Demographic data (age, gender, time with IFX) daily activities, physical activity (BASDAI and BASFI) and laboratory data (ESR and CPR) were collected at the baseline visit prior to tapering, at the next infusion following dose reduction and the last infusion (between November 1st 2014 and December 31st, 2016).

Results: We included 18 patients (16 men) on IFX treatment with EA (16) or axial APs (2). The medians of age and time of evolution were 50.79 years (41.8-55.1) and 9.5 years (7.2-11.5), respectively. Table 1 shows the clinical and laboratory data obtained at the baseline visit, the next infusion and the last infusion. Fourteen patients $(87.9 \%)$ continued with the dose of $4 \mathrm{mg} / \mathrm{kg} / \mathrm{infusion}$ and are maintained in clinical remission. Four patients returned to the dose of 5 $\mathrm{mg} / \mathrm{kg} / \mathrm{infusion}$ due to loss of efficacy at dose reduction, with a mean follow-up of 17.6 months (17.0-19.1). Clinical remission was again achieved in the 4 patients, although one of them changed biological therapy due to loss of efficacy of IFX after 3 infusions with $5 \mathrm{mg} / \mathrm{kg} /$ infusion.

Table 1. Clinical and laboratory data during follow-up

\begin{tabular}{lccc}
\hline & Baseline & Next Infusion & Last Infusion \\
\hline BASDAI median (RI) & $3,1(1,45-4,45$ & $4(1,4-4,25)$ & $4,1(1,65-6,15)$ \\
BASFI median (RI) & $2,8(1,1-4,5)$ & $3,6(1,8-4,25)$ & $2,8(1-5)$ \\
ESR (mm/h) median (RI) & $6,5(3-11,25)$ & $4,5(3-11,5)$ & $12,5(6,5-16,75)$ \\
CPR (mg/dl) median (RI) & $0,2(0,2-0,55)$ & $0,3(0,1-0,4)$ & $0,2(0,1-0,72)$ \\
\hline
\end{tabular}

Conclusions: In our patients with spondyloarthritis dose reduction of IFX was well tolerated and safe, maintaining the clinical response measured by BASDAI and BASFI. In 3 out of 4 patients who worsened upon dose reduction, the 5 $\mathrm{mg} / \mathrm{kg} /$ infusion dose recovered clinical remission.

References:

[1] Janta I et al. Clin Rheumatol. 2015;34: 935-42.

[2] Baraliakos X et al. RMD Open. 2016;2: e000272.

Disclosure of Interest: None declared

DOI: 10.1136/annrheumdis-2017-eular.6554

\section{AB0696 RETENTION RATES OF ADALIMUMAB, ETANERCEPT, AND INFLIXIMAB AS FIRST- OR SECOND-LINE BIOTHERAPIES FOR SPONDYLOARTHRITIS PATIENTS IN DAILY PRACTICE IN AUVERGNE (FRANCE)}

M. Soubrier ${ }^{1}$, B. Castagné ${ }^{1}$, B. Pereira ${ }^{2}$, A. Fan ${ }^{1}$, T. Frayssac $^{1}$, M. Couderc ${ }^{3}$, S. Malochet-Guinamand ${ }^{1}$, S. Mathieu ${ }^{1}$, Z. Tatar ${ }^{1}$, A. Tournadre ${ }^{3}$, J.-J. Dubost ${ }^{1}$ ${ }^{1}$ Rheumatology, C.H.U. HÔPITAL GABRIEL MONTPIED; ${ }^{2}$ DRCI, CHU Gabriel Montpied; ${ }^{3}$ Rheumatology, CHU Hopital Gabriel Montpied, Clermont-Ferrand, France

Background: The use of tumour necrosis factor alpha (TNF- $\alpha$ ) inhibitors or anti-TNFs - has considerably improved the treatment of spondyloarthritis $(\mathrm{SpA})$. The first three of these available anti-TNFs (infliximab, adalimumab, and etanercept) are the most widely used in the treatment of SpA. Their efficacy and safety have been demonstrated in extensive randomised controlled trials (RCTs).Nevertheless, the randomized studies were of short duration and included a selected population that differed from patients treated in daily practice

Objectives: To compare, in real-life settings, the retention rates of the initial anti-TNF treatment (etanercept [ETN], adalimumab [ADA], and infliximab [IFX]) used as first-line biotherapy for spondyloarthritis $(\mathrm{SpA})$, and to evaluate treatment switches to another anti-TNF inhibitor in the event of treatment failure.

Methods: Monocentric retrospective cohort including all SpA patients starting an initial anti-TNF therapy between 2001 and 2015.

Results: Of the $249 \mathrm{SpA}$ patients analysed (135 radiographic cases, 114 non- radiographic), 102 were given ETN, 62 ADA, and 85 IFX. In total, 103 discontinued treatment. The median retention duration was 69.7 months (17- $)$ (ETN: 55.4

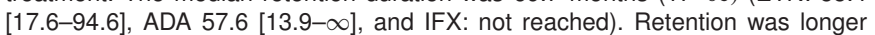
for IFX compared with ETN (HR=0.62 [0.39-0.99]) but non-significant compared with ADA (HR: 0.91 [0.56-1.48]). The percentage of patients continuing treatment after 5 years was $47 \%$ for ETN, $46 \%$ for ADA, and $62 \%$ for IFX. In multivariate analysis, the predictive factors for retention were a low BASDAI score (HR: 1.02 [1.01-1.04]), high CRP levels (HR 0.98 [0.97-0.99]), the concomitant use of disease-modifying therapy (HR: 0.4 [0.21-0.75]), and radiographic SpA (HR: $1.5[1.0-2.52])$. In total, 61 patients switched to another anti-TNF therapy. No difference was observed among the three anti-TNF therapies with regard to the median retention duration, but the retention rate was higher in the event of treatment switches from one monoclonal antibody to another.

Conclusions: The retention rate in SpA patients proved high, and retention for IFX was superior to that of ETN.

Disclosure of Interest: None declared

DOI: 10.1136/annrheumdis-2017-eular.3699

\section{AB0697 IMPACT OF THE BASELINE BATH ANKYLOSING SPONDYLITIS RADIOLOGY HIP INDEX ON THE STRUCTURAL HIP JOINT PROGRESSION AFTER TNF $\alpha$ BLOCKING THERAPY IN SPONDYLOARTHRITIES PATIENTS}

K. Maatallah ${ }^{1}$, M. Sahli ${ }^{1}$, I. Mahmoud ${ }^{2}$, W. Hamdi ${ }^{1}$, O. Saidane ${ }^{2}$, M. Kchir ${ }^{1}$, R. Tekaya ${ }^{2}$, L. Abdelmoula ${ }^{2} .{ }^{1}$ Rheumatology, Kassab university hospital; ${ }^{2}$ Rheumatology, Charles Nicolle university hospital, Tunis, Tunisia

Background: One of the major goals of treatment of spondyloarthrites $(\mathrm{SpA})$ is to prevent or slow the radiographic damage.The results of clinical trials raised expectations that TNFi are effective not only on clinical and biological parameters of the disease but may also have structural effect.

Objectives: We assessed whether the baseline Bath Ankylosing Spondylitis Radiology (BASRI) hip index had effect on structural hip progression under TNF $\alpha$ blockers in SpA patients with hip disease.

Methods: This was a multicentric longitudinal study including SpA patients (ASAS2009) with hip disease under TNF $\alpha$ blockers. Anteroposterior X-rays of the pelvis obtained at baseline were compared with X-rays obtained after 5 years [3-10] of continuous TNF $\alpha$ blockers treatment. Radiographic progression of the hip was evaluated by the Bath Ankylosing Spondylitis Radiology Hip Index (BASRI-h), scoring system ( $\min 0=$ no change, $1=$ focal joint space narrowing, $2=$ circumferential joint space narrowing $>2 \mathrm{~mm}, 3=$ circumferential joint space narrowing $\leq 2 \mathrm{~mm}$ or bone-on-bone apposition of $<2 \mathrm{~cm}$ and $\max 4=$ bone deformity or bone-on-bone apposition of $\geq 2 \mathrm{~cm}$ ) and the hip joint space width (assessed by the average of measurements at three distinct sites between the acetabulum and femoral head)[1]. The median progression of the hip joint space was chosen as cut-off to define the structural evolution, it was $0.3 \mathrm{~mm}$. A good response of the hip was defined by a stabilization or a decrease of the hip joint space less than $0.3 \mathrm{~mm}(\mathrm{RH}+)$.A poor response was defined by a decrease of the hip joint space $>0.3 \mathrm{~mm}(\mathrm{RH}-)$.

Results: 48 patients were included $(81 \%$ male). The average age was $40.7 \pm 11$ years. The mean age at the onset of the disease was $25.8 \pm 10$ years. Hip involvement was bilateral in $77 \%$ of cases. At baseline, the mean BASRI hip index was $2 \pm 0.8$. The BASRI hip score was 1 in $26 \%, 2$ in $51 \%, 3$ in $18 \%$ and 4 in $5 \%$ of patients. The average of hip joint space width at baseline was $3.4 \pm 1.2 \mathrm{~mm}$. Infliximab was the most prescribed TNF $\alpha$ blocker (48\%) followed by Etanercept (37.5\%) and Adalimumab (14.5\%).After 5years, the mean BASRI hip index remained stable $2 \pm 0.8$, the BASRI hip score was 1 in $23 \%, 2$ in $50 \%, 3$ in $14 \%$ and 4 in $13 \%$ ( $p=n s$ ). The variation of hip joint space width was $-0.294 \mathrm{~mm}$ ( $p=n s$ ). 29 patients were $\mathrm{RH}+$. The BASRI hip index $2 \pm 0.8$ and $2.1 \pm 0.9$ in $\mathrm{RH}+$ and $\mathrm{RH}$ - patients respectively with no statistically significant difference.

Conclusions: According to our study the structural hip joint progression under TNF $\alpha$ blockers is not influenced by the baseline BASRI hip index.

References:

[1] Konsta M,Sfikakis PP, Bournia VK, Karras D, lliopoulos A.Clin Rheumatol (2013) 32:1229-1232

Disclosure of Interest: None declared

DOI: 10.1136/annrheumdis-2017-eular.6459

\section{AB0698 COMPLEMENTARY AND ALTERNATIVE MEDICINE USAGE AND ASSOCIATED FACTORS IN ANKYLOSING SPONDYLITIS: PRELIMINARY RESULTS OF A CROSS-SECTIONAL STUDY}

F.I. Cinar ${ }^{1}$, O. Ozdemir ${ }^{2}$, S. Yilmaz ${ }^{3}$, N. Ozen ${ }^{4}$, G. Bagcivan ${ }^{5}$, I. Aydoğan ${ }^{6}$, A.G. Yalcin ${ }^{6}$, E. Tekgoz ${ }^{3}, \mathrm{M}$. Cinar ${ }^{3}{ }^{1}{ }^{1}$ Gulhane School of Nursing, University of Health Sciences; ${ }^{2}$ Department of Nursing, Ankara Yildirim Beyazit University, Faculty of Health Sciences; ${ }^{3}$ Department of Internal Medicine, Division of Rheumatology, University of Health Sciences, Gulhane Medical Faculty, Ankara; ${ }^{4}$ University of Health Sciences, Okmeydani Training and Research Hospital, Kasimpasa Building, Istanbul; ${ }^{5}$ Department of Internal Medicine; ${ }^{6}$ Division of Rheumatology, Gulhane Training and Research Hospital, Ankara, Turkey

Background: Several surveys indicate that the complementary and alternative medicine (CAM) use is especially prevalent in patients with chronic painful 
conditions like ankylosing spondylitis (AS). Despite good treatment options such as tumor necrosis factor alpha (TNF $\alpha$ ) inhibitors in AS, it is seen that patients have applied for CAM use for many reasons including local regulatory funding requirements, potential risks and accessibility of biological treatments. Few studies have examined the frequency of CAM use, and associations between demographic and disease-related factors of it in AS.

Objectives: To investigate the CAM usage of patients with AS and to determine the associated factors.

Methods: Total of 123 patients with AS, who were being followed in a tertiary rheumatology outpatient clinic, were included to the study. The demographic and clinical features along with the behaviors about the CAM usage of the patients agreeing to participate were recorded to the "Patient Assessment Form". The activity of the disease were determined with doctor global assessment (numeric visual analog scale (nVAS; 0-10), and Routine Assessment of Patient Index Data (RAPID)-3 score. The treatment adherence of the patients was assessed with the Morisky Green Levine Scale.

Results: One hundred eleven patients (\%90.2) were male, and mean age was $36.5 \pm 8.8$ years. The mean disease duration and mean delay in diagnosis were $10.9 \pm 6.4$, and $3.7 \pm 3.9$ years, respectively. The mean RAPID3 score, doctor and patient global assessment were; $9.9 \pm 5.3,2.8 \pm 1.9$, and $4.6 \pm 2.7$, respectively. While 79 patients (\%64.2) were on anti-TNF treatment, 76 patients were receiving NSAIDs, and 35 patients (\%28.5) reported an adverse event related with the treatment. Forty-five patients (\%36.6) reported to use any CAM (previous or current) (Table1). The reasons reported by the patients for the usage of CAM; media in $\% 13$, recommendations from family members or relatives in \%10.6. It has been found that in married patients, the ones with lower the Morisky Green Levine Scale score (high adherence), CAM usage was statistically high $(p<0.05)$. Receiving NSAIDs or anti-TNF agents was not statistically associated with CAM usage. The underlying expectations for the usage of CAM were; considering it might be helpful in \%27.6; considering it might heal in \%17.9; to relieve the pain in \%14.6; and preventing to deteriorate the disease status in $\% 12.2$.

Table 1. Types of CAM use

\begin{tabular}{lcc}
\hline CAM Type & $\mathrm{n}^{*}$ & $\%$ \\
\hline Plants and herbs & 31 & 25.2 \\
Massage & 13 & 10.6 \\
Spa & 10 & 8.1 \\
Praying/spiritual approach & 6 & 4.9 \\
Cupping & 3 & 2.4 \\
Imagining & 2 & 1.6 \\
Naturapati & 2 & 1.6 \\
Acupuncture & 1 & 0.8 \\
\hline
\end{tabular}

CAM, complementary and alternative medicine. ${ }^{*}$ There are patients marked the method more than one.

Conclusions: In our study, we found that approximately one third of our AS patients were using CAM. When compared with the literature related with other diseases, CAM usage in AS patients was somewhat lower. Our results have demonstrated that treatment adherence was higher in those using concomitantly CAM in their therapy.

Disclosure of Interest: None declared

DOI: 10.1136/annrheumdis-2017-eular.4196

\section{AB0699 EFFECTS OF GLOBAL POSTURAL REEDUCATION EXERCISE AND ANTI-TNF TREATMENTS ON DISEASE ACTIVITY, FATIGUE, MOBILITY, SLEEP QUALITY AND DEPRESSION IN PATIENTS WITH ACTIVE ANKYLOSING SPONDYLITIS (PROSPECTIVE-CONTROLLED TRIAL)}

N.H. Coksevim, D. Durmus, O. Kuru. Physical Therapy and Rehabilitation, 19 Mayis University Medical Faculty, Samsun, Turkey

Background: Ankylosing spondylitis (AS) is chronic inflammatory disease that affects primarily the spine and the sacroiliac joints. ASAS/EULAR guidelines describe regular exercise as the cornerstone of non-pharmacological treatment and pharmacological treatments including non-steroidal anti-inflammatory drugs as first-line therapy, and a tumour necrosis factor (TNF) alpha inhibitor (anti$\mathrm{TNF} \alpha$ ) as second-line medication in patients with persistently high disease activity despite conventional pharmacological treatment in patients with AS.

Objectives: The purpose of this study was to investigate the effects of combination therapy with global postural reeducation exercise (GPR) and Anti-TNF treatments on pain, disease activity, mobility, fatigue, sleep quality, and depression in patients with active AS.

Methods: 60 active AS patients who meet the criteria of Modified New York and/or ASAS axial spondyloarthropathy were included in the study. Patients were divided into 3 groups. The first group was given anti-TNF therapy plus GPR exercise program. The 2nd group was given anti-TNF and conventional exercise therapy. The 3rd group was given routine exercise program along with their existing treatments (NSAIDs and/or SLZ). Following inventories are used for clinical evaluation: for disease activity - Bath Ankylosing Spondylitis Disease Activity Index (BASDAI), for functionality - Bath Ankylosing Spondylitis Functional Index (BASFI), for mobility - lumbar Schober, chest expansion, hand-finger to floor distance, for fatigue - fatigue Multidimensional Assessment Questionnaire (MAF), for sleep quality - Pittsburgh sleep quality index (PSQI), for depression
- Beck depression Inventory (BDI). All patients were evaluated before treatment and at 3 months.

Results: The demographic characteristics of the patients were compared and there was no significant difference between the groups. The improvements in all parameters were better in both groups receiving exercise and anti-TNF therapy than in the control group after treatment compared with baseline. The Anti-TNF + GPR exercise therapy resulted in greater improvements than the anti TNF+ conventional exercise therapy in pain, and mobility parameters.

Conclusions: Anti-TNF therapy and exercise were efficient in both groups on improving pain, disease activity, fatigue, sleep quality, and depression. However, the improvements in pain and mobility were greater in the active AS patients with GPR exercise method. Therefore motivated patients should be encouraged to perform this exercise program.

\section{References:}

[1] Lubrano E, Spadaro A, Amato S, et al. Tumour necrosis factor alpha inhibitor therapy and rehabilitation for the treatment of ankylosing spondylitis: A systematic review. Seminars in Arthritis and Rheumatism. 44(2015)542-550.

Disclosure of Interest: None declared

DOI: 10.1136/annrheumdis-2017-eular.6379

\section{AB0700 EFFICACY AND DRUG SURVIVAL OF ANTI-TUMOUR NECROSIS FACTOR-ALPHA THERAPIES IN PATIENTS WITH SPONDYLO- ARTHRITIS: ANALYSIS FROM THE THAI RHEUMATIC DISEASE PRIOR AUTHORIZATION (RDPA) REGISTER}

P. Chiowchanwisawakit $^{1}$, W. Katchamart ${ }^{1}$, P. Chevaisrakul ${ }^{1}$,

P. Narongroeknawin ${ }^{2}$, W. Louthrenoo ${ }^{3}$, M. Osiri $^{4}$ on behalf of the Thai

Rheumatism Association. ${ }^{1}$ Mahidol University; ${ }^{2}$ Phramongkutklao Hospital and

College of Medicine, Bangkok; ${ }^{3}$ Chiang Mai University, Chiang Mai;

${ }^{4}$ Chulalongkorn University, Bangkok, Thailand

Background: Treatment recommendations for patients with spondyloarthritis $(\mathrm{SpA})$ who inadequately respond to non-steroidal anti-inflammatory drugs (NSAIDs) and/or traditional disease-modifying antirheumatic drugs (DMARDs) are anti-tumour necrosis factor-alpha therapy (TNFi). There has been no data on the long-term efficacy and safety of TNFi in Thai patients with SpA.

Objectives: To evaluate the long-term efficacy and safety of the first TNFi in real-life practice and to identify the risk factors related to drug discontinuation in Thai patients with SpA from the RDPA registry.

Methods: Patients who fulfilled the 1984 Modified New York criteria for ankylosing spondylitis (AS), CASPAR criteria or Moll and Wright criteria for psoriatic arthritis (PsA) and the European Spondyloarthropathy Study Group Criteria or Modified Amor criteria for undifferentiated SpA (uSpA), and were prescribed the first TNFi between December 2009 and October 2014 in the RDPA registry were enrolled. Baseline demographic and clinical data were retrieved. A Cox proportional hazard model was used to identify the factors associated with discontinuation. The P-value of $<0.05$, two-sided was considered statistically significant.

Results: Of the 142 patients included, 97 had AS, 41 had PsA, and 4 had uSpA. Most AS patients were male (54.6\%) with mean (SD) age of 44.6 (10.6) years, median $\left(\mathrm{P}_{25}-\mathrm{P}_{75}\right)$ baseline BASDAI was $6.5(5.6,8.2)$ [from a $10-\mathrm{cm}$ visual analog scale (VAS)], and median baseline patient global assessment (bPGA) was $7.2\left(\mathrm{P}_{25}-\mathrm{P}_{75} 6.0,8.0\right)$ (from a 10-cm VAS). For PsA patients, most were female $(68.3 \%)$ with mean age of 52.6 (SD 12.2) years, median baseline BASDAI was $6.6\left(\mathrm{P}_{25}-\mathrm{P}_{75} 4.9,7.4\right)$ in patients with active axial involvement and median baseline number of joint involvement was $13.5\left(P_{25}-P_{75} 6,18.3\right)$ joints per patient with active peripheral joint involvement. The Efficacy of the TNFi treatment was good and it was increased over time in AS and PSA patients (figure 1). During the 5-year follow-up, AS, PsA, and USpA patients had comparable discontinuation rate of their first TNFi treatment [25 (26\%) in AS, $14(34 \%)$ in PsA, and $1(25 \%)$ in uSpA; $\mathrm{p}=0.82]$. In univariate analysis, leflunomide use, and $\mathrm{bPGA}<3$ comparing to $>6$ (from a 10-cm VAS) were associated with the discontinuation of TNFi in AS patients with hazard ratio $(\mathrm{HR})(95 \% \mathrm{Cl})$ of $2.56(1.13,5.81)$ and 8.59 $(1.82,40.65)$, respectively. For the patients with PsA, only infliximab use was associated with TNFi discontinuation with $\mathrm{HR}$ of $4.79(95 \% \mathrm{Cl} 1.33,17.20)$ in univariate analysis. The reasons for TNFi discontinuation were good response $(38 \%)$, serious adverse effects (SAE) $(30 \%)$, non-adherence $(20 \%)$, and lack of efficacy (13\%). Among SAE, 58\% was infectious causes $(57 \%$ tuberculosis and $43 \%$ non-mycobacterium infections). The others were non-infectious causes.

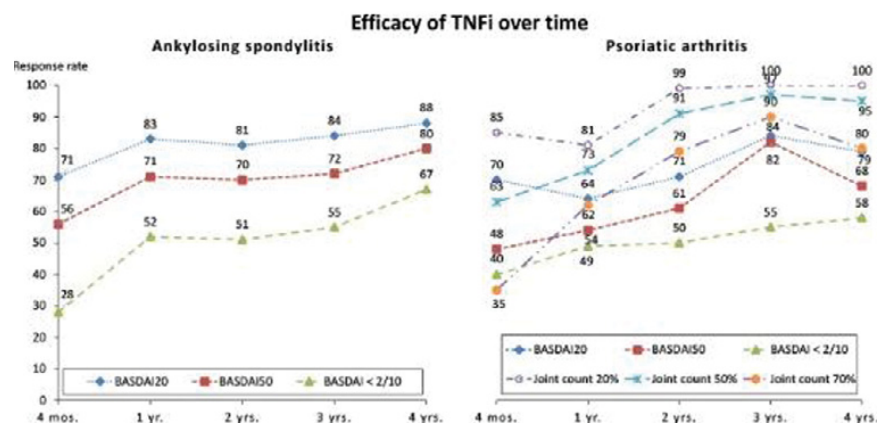

